\title{
THE ROLE OF UNESTERIFIED FATTY ACID TRANSPORT IN CHYLOMICRON METABOLISM
}

\author{
By DONALD S. FREDRICKSON, DUNCAN L. MCCOLLESTER, AND KATSUTO ONO \\ (From the Section on Metabolism, Laboratory of Cellular Physiology and Metabolism, National \\ Heart Institute, National Institutes of Health, Bethesda, Md.)
}

(Submitted for publication October 29, 1957 ; accepted June 12, 1958)

In a study to determine the early fate of absorbed fat, previously reported from this laboratory, observations were made on the removal of chylomicra containing triglyceride labeled with palmitic acid-1- $\mathrm{C}^{14}$ from the plasma of the anesthetized $\operatorname{dog}(1)$. It was found that the triglyceride fatty acids (TGFA) rapidly appeared in the albumin-bound unesterified fatty acid fraction (UFA) of the plasma. The turnover of plasma UFA also was estimated from the rate of disappearance of palmitate- $\mathrm{C}^{\mathbf{1 4}}$ immediately after injection of the albumin-bound form and was found to be very high. It was concluded that the clearing of chylomicra was intimately associated with hydrolysis of the triglycerides and retransport of their constituent fatty acids in plasma as UFA. Since these experiments did not include measurement of oxidation of the administered fatty acids it was not possible to assess the relative importance of the UFA pathway in the subsequent metabolism of TGFA.

The experiments described in the present paper were made primarily to investigate this relationship. For this purpose, the oxidation and plasma turnover of $\mathrm{C}^{14}$-palmitate administered as TGFA and as UFA have been compared in carefully controlled experiments.

\section{METHODS}

Substrates. Chylomicra containing palmitate-1- $\mathrm{C}^{14}$ labeled fatty acids were obtained from donor dogs prepared as previously described (1). Chylomicra as defined here included that lipoprotein fraction which packed firmly at the top of the tube after chyle was layered under saline at density 1.006 and centrifuged for 30 minutes at $100,000 \times \mathrm{G}$. The material obtained in this way and washed twice more in saline by the same process consisted of more than 90 per cent triglyceride and 0.5 to 1 per cent protein. Chemical analyses (vide infra) indicated that 98 to 99 per cent of the radioactivity was present in the triglyceride fraction and that no more than 0.2 per cent was present as unesterified fatty acid.

The total lipid in a single administration of chylo- micra was 13 to $80 \mathrm{mg}$. per kilogram body weight (Table I), suspended in $20 \mathrm{ml}$. of saline and injected intravenously over a 10 to 15 second period. This amount of lipid provided the minimum amount of radioactivity necessary for extended measurements of blood UFA radioactivity, but probably exceeded the usual physiological rate of entry of chylomicra into the blood since the average donor animal used delivered about $5 \mathrm{mg}$. of chylomicron lipid per kilogram body weight per minute from the thoracic duct fistula. In one experiment $1.5 \mathrm{mg}$. of lipid per kilogram per minute was infused continuously for a two hour period.

Palmitic acid-1-C $\mathrm{C}^{14}$ was obtained from the Nuclear Instrument and Chemical Company, Chicago. Counter current distribution indicated that approximately 95 per cent of the radioactivity was present in palmitic acid, the remainder in highly polar acids. Two preparations were used, having approximate specific activities of 2.54 and 20.0 mc. per $\mathrm{mM}$.

Unesterified palmitic acid-1-C $\mathrm{C}^{\mathbf{1 4}}$ was prepared as the albumin complex as follows: Approximately $6 \mathrm{mg}$. (0.02 milliequivalent) of the potassium salt was dissolved in ethanol. Three $\mathrm{ml}$. of isotonic saline was added and the ethanol evaporated. The warm saline solution was mixed quickly with $20 \mathrm{ml}$. of dog plasma, sufficient to provide an estimated equimolar ratio of albumin to UFA. The serum utilized was obtained from a dog 30 minutes after the administration of glucose and insulin to obtain the lowest possible concentration of endogenous UFA. The total quantity of unesterified fatty acid injected in the optically clear solutions represented roughly 2 to 4 per cent of the amount present in the total plasma volume of the recipients.

Recipients. The recipients were either male or female mongrel dogs. "Carbohydrate loaded" dogs (Table I) were given a diet consisting of dextrose in water and low-fat bread for four days and an infusion containing 25 grams of glucose and 10 units of regular insulin for 30 minutes preceding the experiment. "Fasted" animals were fed a diet consisting of bacon for four days followed by the withdrawal of all food for 24 hours. A saline infusion was substituted for the dextrose given the "carbohydrate-loaded" animals, and all animals received isotonic saline at a rate of $0.5 \mathrm{ml}$. per minute following injection of the labeled substrates. The dogs were maintained in light anesthesia throughout the experiment by intravenous administration of sodium Pentotha1®.

An endotracheal tube connected to a low resistance 
two-way valve was utilized for collection of expired air in Douglas bags. Immediately preceding the injection of the labeled substrate, a sample of air was collected for determination of the respiratory quotient. Blood samples were collected rapidly through an in-lying needle in the femoral artery. Either dried balanced oxalate or heparin was used as anticoagulant. The bloods were immediately chilled and kept at ice temperature.

Separation of chylomicra and UFA. In the experiments in which chylomicron disappearance was measured, the chylomicra were separated by ultracentrifugation of blood, rather than plasma, in order to reduce the number of manipulations involved. Recovery of chylomicra was found to be comparable to that obtained when equivalent amounts of plasma were used. Five ml. aliquots of whole blood were layered under isotonic saline and centrifuged for 18 hours at $105,000 \times G$ in a Spinco No. 40 rotor at $5^{\circ}(2)$. The tubes were then sliced in the clear and colorless zone just below the visible fatty layer at the top. The chylomicra and lipoproteins of density less than 1.006 contained in the supernate were carefully resuspended in saline in graduated vessels. The infranates, including the packed red cells, were resuspended and lyophilyzed without delay for subsequent extraction of LFA. During the course of these experiments it was found that after injection of labeled chylomicra or UFA, about 2 per cent of the total radioactivity and about 15 per cent of the total titratable acidity found in the UFA extracts could not be removed from the suspended cells by three washes with isotonic saline. Since this might have tended to lower blood UFA specific activity below that of plasma, several sets of experiments comparing the metabolism of labeled TGFA and UFA were also performed in which plasma was ultracentrifuged and the UFA extracted from the infranates.

Chemical analyses. Aliquots of the substrate chylomicron suspensions and UFA-albumin solutions were extracted in acetone: ethanol $(1: 1)$. The supernatant lipoproteins from the ultracentrifugal separations were extracted in chloroform: methanol $(2: 1)$. Aliquots were removed for appropriate lipid analyses (3-5) and for assay of radioactivity. Unesterified fatty acids were extracted from the infranates obtained from the ultracentrifugal runs, whole blood or plasma, and red cell suspensions according to the method of Gordon (6). The unesterified fatty acids were further separated from the neutral'lipid in the iso-octane phase by extraction with $1 \mathrm{M} \mathrm{NaOH}$ in 50 per cent ethanol, followed by acidification and re-extraction of the acids into iso-octane according to the method of Borgström (7). The final phase was washed three times with a $1: 2,000$ solution of $\mathrm{H}_{2} \mathrm{SO}_{4}$ before aliquots were removed for titration and counting.

Borgström has reported that his extraction procedure could result in contamination of the UFA phase with lower glycerides. Laurell (8) has also raised the possibility that extraction with unbuffered alkali might produce free fatty acids through hydrolysis of neutral lipid, especially phospholipid. While the original iso-octane extract contained less than 5 per cent of the plasma phospholipids, several other procedures were utilized to ascertain whether the small amounts of labeled UFA observed in the late course of these experiments could be spuriously produced by the method of extraction employed, or represent radioactivity in lower glycerides contained in the "UFA extract."

Test mixtures containing purified palmitic acid, tri-, di-, and monopalmitin were taken through the combined extraction procedures. The final "UFA extract" contained 99 per cent of the added palmitic acid, 10 per cent of added monopalmitin, and less than 1 per cent of the added higher glycerides. An additional purification step was therefore utilized in two experiments (Dogs C-5 and $\mathrm{U}-9$ ) to exclude the possibility of contamination of the UFA fraction by lower glycerides. In these experiments, the $15 \mathrm{ml}$. "UFA extracts" were shaken with 5 grams of silicic acid in $50 \mathrm{ml}$. extraction tubes. After centrifugation, the iso-octane was decanted. Exactly $20 \mathrm{ml}$. of 15 per cent diethyl ether in iso-octane was shaken with the silicic acid, the suspension again centrifuged, and the solvent decanted. It was determined separately that such an eluate contained approximately 50 per cent of cholesterol palmitate, tripalmitin, labeled palmitic, oleic and linoleic acids previously adsorbed on the silicic acid. No monopalmitin, crude lecithin or cephalin added to the silicic acid could be detected in the eluates. The UFA specific activities obtained with these purified extracts did not differ significantly from those obtained using the simpler combined extraction procedures.

Finally, plasma was obtained from a dog 5 and $120 \mathrm{~min}$ utes after the injection of $50 \mu \mathrm{c}$. of palmitic acid-1- $\mathrm{C}^{\mathbf{1 4}}$. The plasma was extracted in acetone: ethanol $(1: 1)$, the solvent evaporated in z'acuo, and the lipids taken up in ether previously equilibrated with water. The ether solution was then passed through a column containing Amberlite IRC-400, after the method of Savary and Desnuelle (9). All neutral lipids, including monopalmitin and lecithin, were quantitatively eluted from the resin by ether, while 99 per cent of added palmitic acid-1-C $C^{\mathbf{1 4}}$ was retained. The amounts of UFA radioactivity determined by this procedure in the 5 and 120 minute plasma samples did not differ significantly from those obtained in the other experiments where the combined solvent extractions were used.

The concentrations of UFA obtained by titration were corrected to milliequivalents per liter of whole blood or plasma. Estimation of specific activity of the chylomicron triglyceride fatty acids was made by assumption of the mean molecular weight of 260 for the fatty acid moiety. The distribution of radioactivity in the chylomicron lipid was determined by silicic acid chromatography by the method of Hirsch and Ahrens (10).

Radioactivity measurements. Carbon-14 measurements were made at $-10^{\circ} \mathrm{C}$. in a Packard Tri-Carb Scintillation Spectrometer. Aliquots of lipid extracts were dried in vials and $15 \mathrm{ml}$. of phosphor solution (400 mg. per cent diphenyloxazole in toluene) added. In the assay of samples containing only UFA, $50 \mathrm{mg}$. of carrier palmitic acid was added to the aliquots before evaporation 
at steam bath temperature. This amount of material was found to minimize loss of UFA by sublimation without the introduction of quenching.

Total and specific radioactivity of carbon dioxide- $\mathrm{C}^{14}$ in expired air samples collected for 1 to 5 minute periods was determined after direct collection in methyl benzethonium (11). The samples were corrected for quenching to permit comparison with the radioactivity in the lipid samples.

All values for chylomicron, UFA and carbon dioxide radioactivity were further adjusted, by a factor derived from the total radioactivity administered and the weight of the recipient, to a value corresponding to a dose of $10^{8} \mathrm{cpm}$ per kilogram body weight.

\section{RESULTS}

\section{Chylomicron clearance}

The disappearance of radioactivity from the fraction of blood containing chylomicra and other lipoproteins of density less than 1.006 is shown in Figure 1, for both fasted and carbohydrate-fed recipients. The disappearance patterns were reasonably similar. Each curve was complex, and included an initial rapid phase which approximated a straight line when the logarithm of total blood chylomicron radioactivity was plotted against time. During this phase the radioactivity fell to about 10 per cent of the zero time value, with 2.5 to 4.5 minutes required to reach half maximal concentration. Following this, the radioactivity disappeared more slowly for 30 to $\bar{\sigma} \hat{0}$ minutes, beyond which accurate measurements could not be made.

\section{Appearance of radioactivity in the blood UFA}

Radioactivity appeared very quickly in the blood UFA after the injection of labeled chylomicra (Figure 2). The time, $t_{\max }$, when peak specific activity was reached, occurred within 6 to $10 \mathrm{~min}$ utes, or after about three-quarters of the injected triglyceride had been removed from the blood. In two dogs (C-1 and C-2) the appearance of labeled UFA was compared after both fasting and carbohydrate feeding (Figure 2). Carbohydrate feeding did not delay the occurrence of $t_{\max }$, but the maximum concentration of labeled UFA present was only half of that obtained in the fasting state. From the rapid rate with which injected labeled UFA was removed from the blood (Figure 4 ) it could be ascertained that the small amount of "preformed" UFA-C" injected with the chylo-

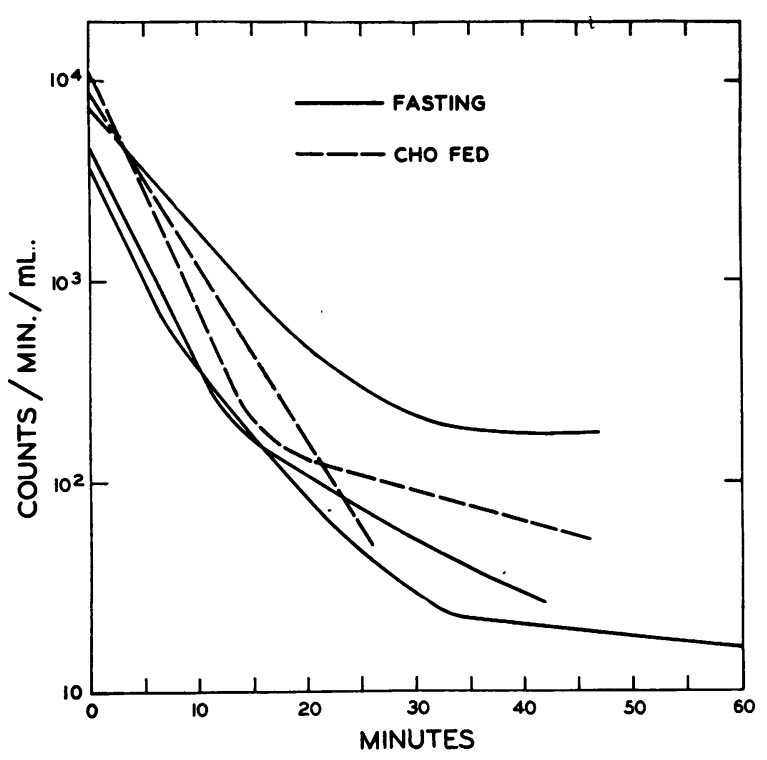

Fig. 1. The Disappearance of Palmitate-1-C ${ }^{14}$-LaBeled Chylomicra from the Blood After Fasting (Dogs C-1,-2 and -3) and After Carbohydrate FeedING (Dogs C-1 AND -2)

The lower four curves were obtained from Dogs C-1 and C-2 (Table I).

micra did not contribute significantly to the levels of radioactivity in UFA arising from TGFA.

\section{The contribution of chylomicron TGFA to cir- culating blood UFA}

The peak specific activity of the UFA in blood after injection of labeled palmitate as chylomicron TGFA varied from 6 to 15 per cent of the calculated specific activity of the infused triglyceride fatty acids. The ratio of peak UFA specific activity to substrate specific activity was much less than had been previously obtained with injection of larger amounts of chylomicra (1).

An experiment was performed to estimate the contribution which fatty acids arising from continuously infused chylomicron triglyceride might make to blood UFA. A fasting dog was given approximately $1.5 \mathrm{mg}$. of labeled chylomicron TGFA per kilogram body weight per minute by intravenous infusion lasting 120 minutes. After one hour, the blood chylomicron radioactivity and the concentration and specific activity of the blood UFA stayed at constant levels. During this time the UFA specific activity was approximately 10 per cent of that of the infused TGFA-C ${ }^{14}$. In this 


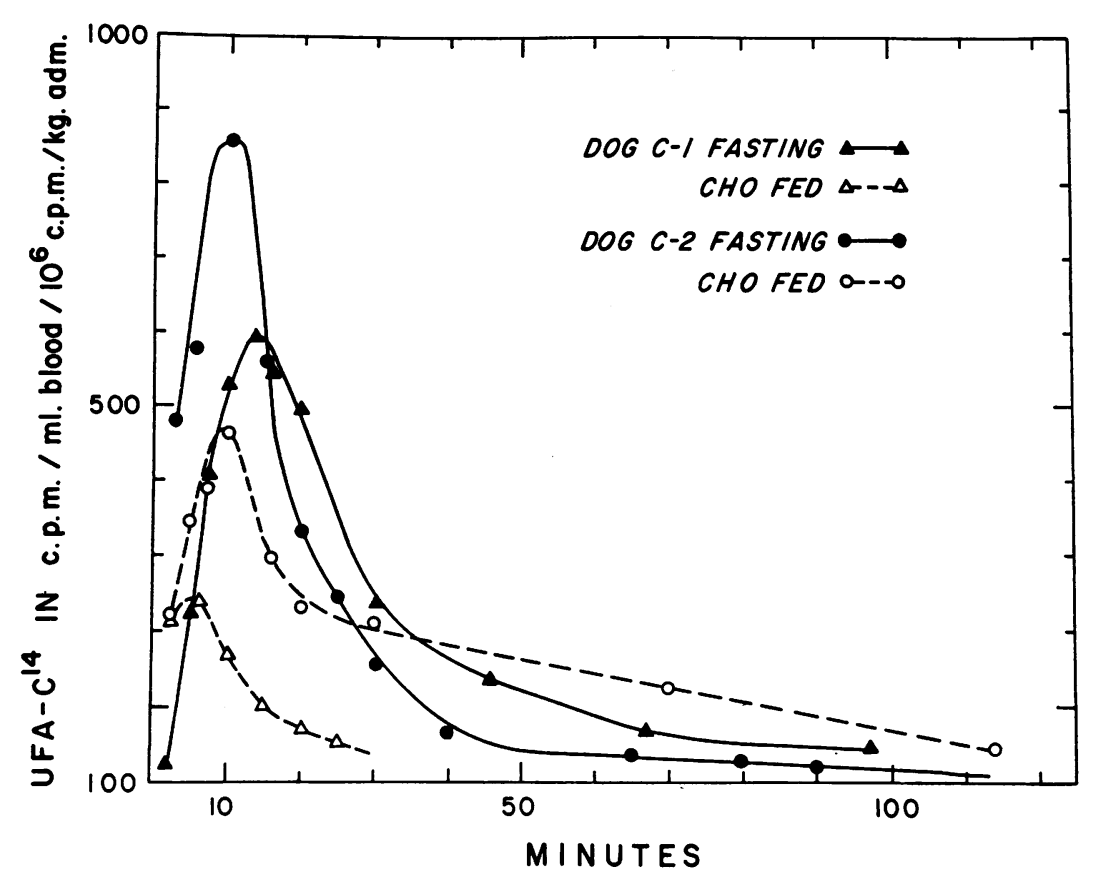

Fig. 2. The Appearance of Radioactivity in Blood UfA After Administration of Palmitate-1-C ${ }^{14}$ as Chylomicron TGFA

simulation of physiological fat absorption, then, not more than 1 UFA molecule out of 10 in the blood appeared to be coming from the infused chylomicron TGFA.

\section{The oxidation of chylomicron TGFA}

As was reported in a preliminary communication (12), the oxidation of palmitic acid-1- $\mathrm{C}^{14}$ injected as chylomicron TGFA began without significant delay. Similar findings have also been reported in the rat $(13,14)$. Specific activitytime curves for expired $\mathrm{C}^{14} \mathrm{O}_{2}$ are shown in Figure 3. Maximum specific activity was reached 35 to 70 minutes after injection, and was followed by a slow steady decline. In the same two dogs compared after both fasting and carbohydrate feeding, the maximum outputs of labeled carboxyl carbon (in counts per minute per minute) were increased 3.6-fold (Dog C-1) and 1.7-fold (Dog $\mathrm{C}-2$ ) by fasting. Thus, as the data in Tables I and II also indicate, a dog such as C-1, tested under extreme differences in nutritional state, tended to spare triglyceride fatty acids when adequate glucose was available.

To determine the relationship of labeled carboxyl carbon appearing in the blood as UFA to that appearing in the expired $\mathrm{CO}_{2}$ the metabolic behavior of labeled palmitate injected as UFA was next examined.

\section{Metabolism of albumin-bound palmitic acid-C $C^{14}$}

The disappearance of labeled palmitic acid from the blood after intravenous injection as UFA is shown in Figures 4 and 5. The form of the disappearance curves in dogs was very similar to that observed in man. An interpretation of UFA metabolism, based on similar tracer data, has been presented elsewhere $(12,15)$. In these experiments, when the logarithm of UFA radioactivity is plotted against time, the earliest portion of the curve approximates a straight line for 2 to $5 \mathrm{~min}$ utes. A fractional turnover rate, $k$, for disappearance of UFA from the blood may be derived from the slope of this line. From the product of $k$ (minutes $^{-1}$ ) $\times$ UFA concentration (mEq. per liter) $\times$ plasma volume (liters) a plasma turnover of UFA (in mEq. per minute) is obtained. This estimation includes the assumption that all UFA in the blood disappears at the rate observed for the tracer acid. A similar turnover rate, which is dependent on the UFA concentration, has been observed for labeled palmitic, oleic and linoleic acids in man 


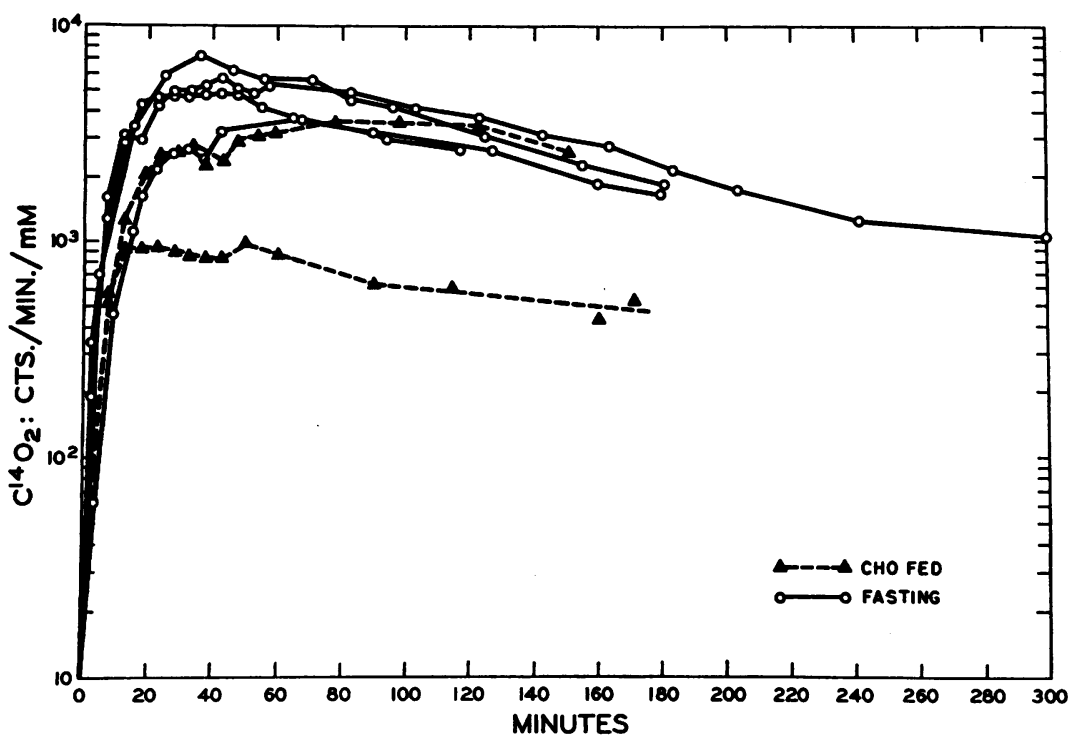

Fig. 3. The Appearance of Radioactivity in Expired $\mathrm{CO}_{2}$ After Administration of Palmitate-1-C ${ }^{14}$ as Chylomicron TGFA

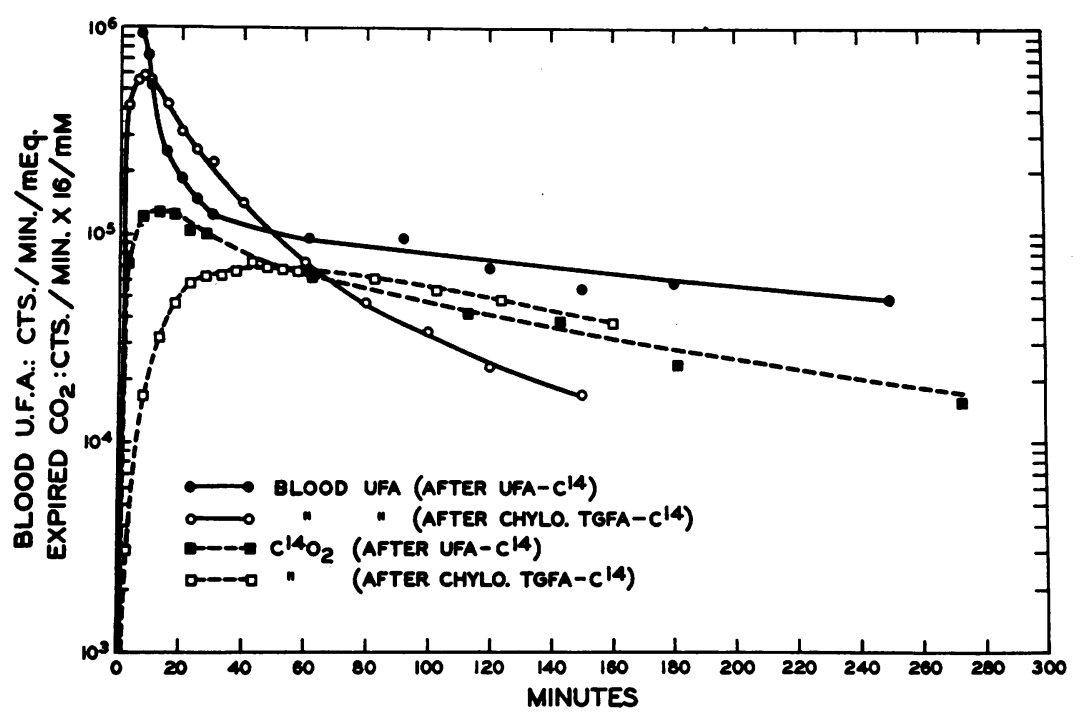

Fig. 4. Comparison of Radioactivity Obtained in Blood UfA and Expired $\mathrm{CO}_{2}$ After Administration of Palmitic Acid-1-C ${ }^{14}$ as Chylomicron TGFA AND AS UFA

(15). The later complexity of the UFA disappearance curve has been interpreted to result from recycling of labeled UFA molecules back into the plasma (15).

The specific activity of labeled $\mathrm{CO}_{2}$ in the expired air after the albumin-palmitate complex was injected is also shown in Figure 4. From Table II it can be seen that 20 to 30 per cent of the UFA carboxyl carbon was excreted as $\mathrm{CO}_{2}$ within three hours after first entering the plasma of fasting dogs.

6. Differences in the metabolism of palmitic acid injected as TGFA or UFA

Since it may be assumed that, once a labeled palmitate molecule is present in the plasma as UFA, its subsequent metabolic fate will be independent of its origin, it should be possible to as- 
TABLE I

Status of animals receiving palmitate-1-C $C^{14}$ as chylomicron triglyceride or as albumin-bound unesterified fatty acid (UFA)

\begin{tabular}{|c|c|c|c|c|c|c|}
\hline Dog & Wgt. & $\begin{array}{c}\text { Form of } \\
\text { palmitate-1-C }\end{array}$ & $\begin{array}{c}\text { Nutritional } \\
\text { status }\end{array}$ & $\begin{array}{c}\text { Respiratory } \\
\text { quotient }\end{array}$ & $\underset{\text { UFA }}{\text { Plasma }}$ & $\begin{array}{c}\text { Total } \\
\text { lipid } \\
\text { infused }\end{array}$ \\
\hline \multirow[t]{2}{*}{ C-1 } & $\begin{array}{l}K g . \\
15.6\end{array}$ & \multirow{2}{*}{$\begin{array}{c}\text { Chylomicron } \\
\text { TGFA* }\end{array}$} & Fasted & 0.6 & $\begin{array}{c}m E q . / L . \\
1.78\end{array}$ & $\begin{array}{c}m g . / K g . \\
70\end{array}$ \\
\hline & 15.3 & & $\begin{array}{c}\text { Carbohydrate } \\
\text { fed }\end{array}$ & 1.0 & 0.41 & 63 \\
\hline \multirow[t]{2}{*}{$\mathrm{C}-2$} & 16.7 & $\begin{array}{c}\text { Chylomicron } \\
\text { TGFA }\end{array}$ & Fasted & 0.6 & 1.46 & 65 \\
\hline & 16.7 & $\begin{array}{c}\text { Chylomicron } \\
\text { TGFA }\end{array}$ & $\begin{array}{c}\text { Carbohydrate } \\
\text { fed }\end{array}$ & 0.9 & 0.97 & 68 \\
\hline $\mathrm{C}-3$ & 20.0 & $\begin{array}{c}\text { Chylomicron } \\
\text { TGFA }\end{array}$ & Fasted & 0.6 & 0.64 & 45 \\
\hline $\mathrm{C}-4$ & 14.3 & $\begin{array}{c}\text { Chylomicron } \\
\text { TGFA }\end{array}$ & Fasted & 0.6 & & 13 \\
\hline C-5 & 11.5 & $\begin{array}{c}\text { Chylomicron } \\
\text { TGFA }\end{array}$ & Fasted & 0.8 & 0.70 & 67 \\
\hline $\mathrm{U}-7$ & $\begin{array}{l}12.3 \\
14.9\end{array}$ & $\begin{array}{l}\text { UFA } \\
\text { UFA }\end{array}$ & $\begin{array}{c}\text { Fasted } \\
\underset{\text { Carbohydrate }}{\text { fed }}\end{array}$ & $\begin{array}{l}0.6 \\
1.0\end{array}$ & $\begin{array}{l}0.77 \\
0.41\end{array}$ & $\begin{array}{l}<1 \\
<1\end{array}$ \\
\hline $\begin{array}{l}\text { U-8 } \\
\text { U-9 }\end{array}$ & $\begin{array}{l}16.5 \\
16.5\end{array}$ & $\begin{array}{l}\text { UFA } \\
\text { UFA }\end{array}$ & $\begin{array}{l}\text { Fasted } \\
\text { Fasted }\end{array}$ & $\begin{array}{l}0.6 \\
0.8\end{array}$ & $\begin{array}{l}0.50 \\
0.67\end{array}$ & $\begin{array}{l}<1 \\
<1 \text { (UFA) } \\
65 \text { (TGFA) }\end{array}$ \\
\hline
\end{tabular}

* Triglyceride fatty acid.

certain from these data whether or not retransport as UFA must occur before chylomicron triglyceride fatty acids are oxidized. This may be approached in two ways: 1) by a comparison of specific activities observed in blood or plasma UFA and expired $\mathrm{CO}_{2}$, and 2) by comparison of the turnover or flux of labeled UFA in the plasma with that observed in the expired $\mathrm{CO}_{2}$ after injection of palmitate- $\mathrm{C}^{\mathbf{1 4}}$ in the two substrate forms.

In Figure 4 are presented specific activities in

TABLE II

Total carboxyl-carbon-14 excreted by dogs in expired air as $\mathrm{CO}_{2}$

\begin{tabular}{|c|c|c|c|c|}
\hline \multirow[b]{2}{*}{ Dog } & \multirow{2}{*}{$\begin{array}{l}\text { Nutritional } \\
\text { status }\end{array}$} & \multirow{2}{*}{$\begin{array}{c}\text { Form of } \\
\text { palmitate- } \\
1-C^{14}\end{array}$} & \multicolumn{2}{|c|}{$\begin{array}{l}\text { Percentage of radio- } \\
\text { activity excreted as } \mathrm{C}^{14} \mathrm{O}_{2}\end{array}$} \\
\hline & & & $30 \mathrm{~min}$. & $180 \mathrm{~min}$. \\
\hline & & & $\%$ & $\%$ \\
\hline C-1 & Fasting & TGFA & 1.6 & 19 \\
\hline $\mathrm{C}-2$ & Fasting & TGFA & 2.7 & 16 \\
\hline C-3 & Fasting & TGFA & 2.2 & 20 \\
\hline C-4 & Fasting & TGFA & 3.9 & 28 \\
\hline C-5 & Fasting & TGFA & 1.1 & 22 \\
\hline U-7 & Fasting & UFA & 9.8 & 23 \\
\hline U-9 & Fasting & UFA & 8.8 & 29 \\
\hline C-1 & $\begin{array}{l}\text { Carbohydrate } \\
\text { fed }\end{array}$ & TGFA & 0.9 & 5 \\
\hline $\mathrm{C}-2$ & Carbohydrate & TGFA & 0.7 & 15 \\
\hline U-7 & $\begin{array}{c}\text { Carbohydrate } \\
\text { fed }\end{array}$ & UFA & 5.4 & 13 \\
\hline
\end{tabular}

UFA and $\mathrm{CO}_{2}$ from one fasting dog (U-7) given UFA-C $\mathrm{C}^{14}$ and composite data from three fasting dogs ( $\mathrm{C}-1,-2$ and -3$)$ given labeled chylomicra. The $\mathrm{C}^{14} \mathrm{O}_{2}$ specific activities have been multiplied by a factor of 16 to approximate the minimal "obligatory dilution" assumed to occur during the oxidation of a singly-labeled palmitic acid molecule (16). From this figure it may be concluded that palmitic acid injected as either UFA or as chylomicron TGFA was oxidized at similar rates and apparently with similar dilution. As will be seen from the cumulative excretion of labeled carboxyl carbon (Table II) the early delay in reaching maximum specific activity in oxidation of TGFA represented the only difference. A second reasonable conclusion is that all chylomicron TGFA was not retransported in the blood as UFA before it was oxidized. This is based on the observation that the specific activity of the blood UFA derived from TGFA eventually dropped below that of the $\mathrm{C}^{14} \mathrm{O}_{2}$ and stayed there for several hours. During this time, the observed $\mathrm{C}^{14} \mathrm{O}_{2}$ specific activities could not have reasonably come solely from the oxidation of blood UFA in which the radioactivity was more dilute.

The specific activity data obtained in several sets of experiments were also used to calculate the 
flux of labeled carboxyl carbon from plasma as UFA and in expired air as $\mathrm{CO}_{2}$. Data calculated in this way are shown in Figures 5 and 6 for Dogs U-9 and C-5. Dog U-9 also received unlabeled chylomicra simultaneously with UFA-C ${ }^{14}$ (Table I) to permit identical comparison with $\mathrm{C}-5$. The fluxes from plasma as UFA (in counts per minute per minute) were obtained by multiplying the UFA specific activities at time, $t$ (in counts per minute per $\mathrm{mEq}$.), by the plasma UFA turnover (in mEq. per minute) estimated from the plasma UFA "pool" and the turnover rate obtained from the initial slope of the disappearance curve for palmitate- $\mathrm{C}^{\mathbf{1 4}}$ injected as UFA. Since the plasma UFA concentration in the dog receiving labeled TGFA (Figure 6) was the same, it was possible to use the same fractional turnover rate for the flux calculation in

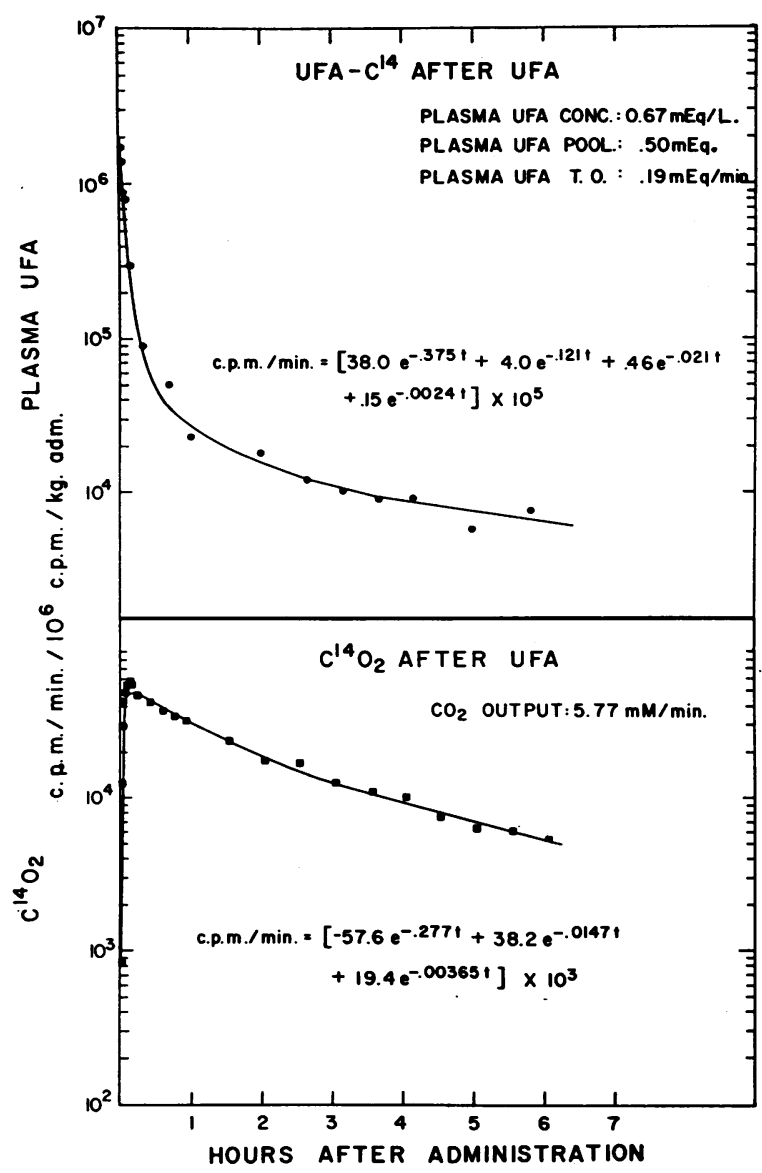

Fig. 5. The Flux of Labeled Carbon from Plasma as UFA and in Expired Air as $\mathrm{CO}_{2}$ After AdminisTRATION OF Palmitic AcId-1-C $\mathrm{C}^{\mathbf{1 4}}$ as UFA

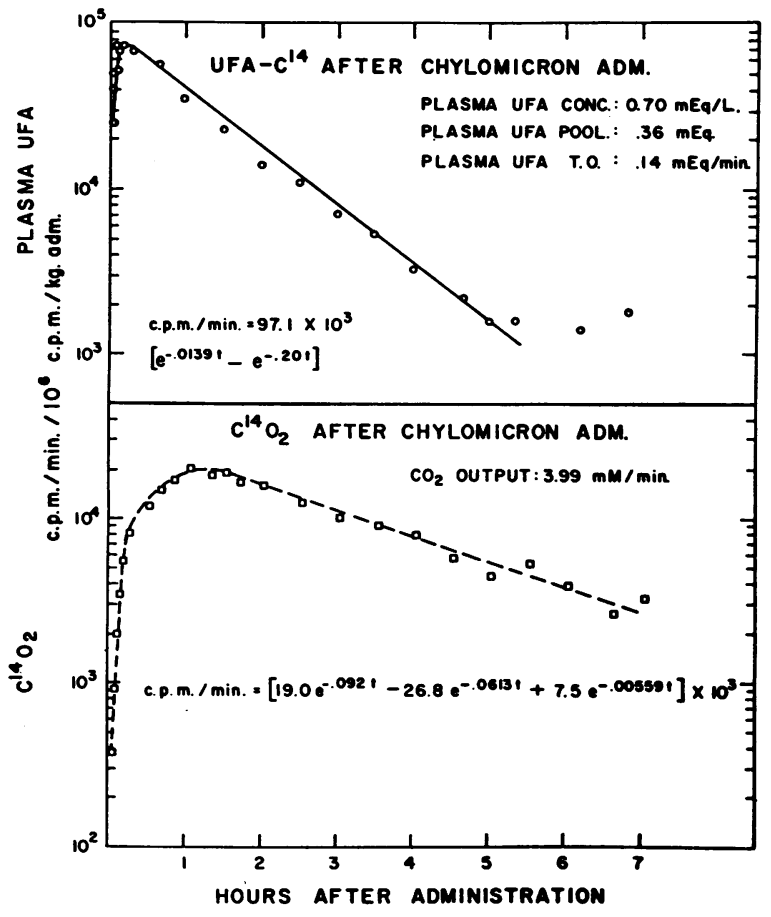

Fig. 6. The Flux of Labeled Carbon from Plasma as UFA and in Expired Air as $\mathrm{CO}_{2}$ After Administration of Palmitate-1-C ${ }^{14}$ as Chylomicron TGFA

this animal (15). The flux of radioactivity in the $\mathrm{CO}_{2}$ was calculated by multiplying the specific activities (in counts per minute per $\mathrm{mM}$ ) by the mean rate of $\mathrm{CO}_{2}$ output (in $\mathrm{mM}$ per minute). A curve was fitted to each plot of flux against time, and an analytical expression consisting of a sum of exponential terms derived. These expressions were then integrated to obtain the total flux during a six hour period of observation. The results of such calculations for the dogs shown in Figures 5 and 6 and for another pair of animals are shown in Table III. It is apparent that the amount of labeled UFA which cycled through the plasma after injection of TGFA-C ${ }^{14}$ was considerably less than after injection of UFA-C ${ }^{14}$ even though comparable amounts of carboxyl carbon were being excreted. Were all of the chylomicron triglyceride fatty acids to have been retransported as UFA before oxidation, the flux of radioactivity in the plasma UFA should have been essentially the same after palmitate-1- $\mathrm{C}^{14}$ was injected in either form. These data are therefore incompatible with the obligatory retransport of chylomicron triglyceride fatty acids 
TABLE III

Comparison of the flux of labeled carboxyl carbon from palmitic acid in plasma UFA and expired $\mathrm{CO}_{2}$

\begin{tabular}{|c|c|c|c|c|c|}
\hline \multirow[b]{2}{*}{ Dog } & \multirow[b]{2}{*}{ Substrate } & \multirow{2}{*}{$\begin{array}{c}\text { Total } \\
\text { dose } \\
\text { C14 }\end{array}$} & \multicolumn{2}{|c|}{ Total C" flux* in: } & \multirow{2}{*}{$\begin{array}{c}\text { Ratio } \\
\text { flux } \\
\text { UFA/CO }\end{array}$} \\
\hline & & & $\begin{array}{c}\text { Plasma } \\
\text { UFA }\end{array}$ & $\overline{\mathrm{CO}_{2}}$ & \\
\hline & & $c p m \times 10^{\circ}$ & \multicolumn{2}{|c|}{$c p m \times 10^{\circ}$} & \\
\hline $\begin{array}{l}\text { U-9† } \\
\text { C-5† } \\
\text { U-1 } \\
\text { C-4 }\end{array}$ & $\begin{array}{l}\text { UFA } \\
\text { TGFA } \\
\text { UFA } \\
\text { TGFA }\end{array}$ & $\begin{array}{l}16.5 \\
11.5 \\
12.3 \\
20.0\end{array}$ & $\begin{array}{r}19.3 \\
6.5 \\
12.6 \\
7.1\end{array}$ & $\begin{array}{l}6.3 \\
3.7 \\
3.0 \\
4.6\end{array}$ & $\begin{array}{l}3.1 \\
1.8 \\
4.0 \\
1.5\end{array}$ \\
\hline
\end{tabular}

* Flux equals $\int_{0}^{t} \gamma \mathrm{dt}$, where $\gamma$ is the sum of exponential terms in the analytical expression derived from the plot of log cpm per minute against time; in plasma UFA-C ${ }^{14}$ $\left(\gamma=\gamma_{\mathrm{a}}\right) ;$ in expired $\mathrm{C}^{14} \mathrm{O}_{2}\left(\gamma=\gamma_{\mathrm{b}}\right)$.

$\dagger$ Time period of observations, 360 minutes.

$\ddagger$ Time period of observations, 240 minutes.

as UFA before oxidation. From the data in Table III it may be inferred that about half of the TGFA oxidized in these experiments had appeared in the blood as UFA. A more rigorous analysis of these and similar data to calculate the extent to which the UFA pathway is utilized and to estimate the rate of hydrolysis of the triglycerides is in preparation (17).

\section{DISCUSSION}

The present experiments were designed to determine the importance of the blood UFA transport system in the metabolism of chylomicron triglyceride. A large fraction of the chylomicron triglyceride fatty acids appeared to be oxidized without first reappearing in the plasma as UFA. In fasting dogs, however, palmitate- $\mathrm{C}^{14}$ injected as chylomicron TGFA or as UFA was oxidized at similar rates and yielded comparable specific activities in the expired $\mathrm{CO}_{2}$, except for an initial lag following TGFA administration. This suggests that much of the triglyceride may have been directly removed and oxidized in the same tissue "pools" as the UFA. Recent experiments by Morris and French, using liver perfusion (18), indicate that this organ, at least, is capable of both removing and oxidizing chylomicron TGFA. Bragdon and Gordon have measured the tissue distribution of palmitate- $\mathrm{C}^{14}$ after intravenous injection as either TGFA or UFA in fasting rats (19). At 10 minutes the radioactivity from both substrates was found principally in liver and skeletal muscle. While it is possible that chylomicron TGFA may be removed at one site and transported elsewhere as neutral lipid, it was previously shown (1) that only small amounts of radioactivity appeared in other plasma lipoproteins after chylomicra were administered. It appears reasonable to conclude that chylomicra represent a plasma vehicle for transport of fat which is directly available for oxidation. These findings also emphasize the importance of examining the possible caloric contribution from fatty acids carried as triglycerides in other lipoproteins.

The effect of carbohydrate on chylomicron metabolism is only partially known. In two dogs studied here after both fasting and carbohydrate loading, the removal of chylomicra was not impaired. The rate of reappearance of triglyceride fatty acids in the blood as UFA, as measured by the time required to reach maximum radioactivity, was also not decreased by carbohydrate feeding, but the total amount of TGFA returned to the blood appeared to be considerably less. This apparent decrease in UFA production may be due to a widely distributed effect of carbohydrate or to shunting of much of the chylomicra to areas where UFA production may be especially diminished by carbohydrate excess. It is of interest in this regard that chylomicra appear to accumulate in the adipose tissue in the rat only after carbohydrate feeding (19), and that release of fatty acids from adipose, which is presumably preceded by hydrolysis, is greatly decreased after carbohydrate feeding (6).

\section{SUMMARY}

The metabolism of palmitic acid-1- $\mathrm{C}^{\mathbf{1 4}}$ has been compared after intravenous administration to dogs in the form of chylomicron triglyceride fatty acids (TGFA) and as the albumin-bound unesterified fatty acid (UFA). The specific activities and fluxes of radioactivity observed in the plasma UFA and in the expired $\mathrm{CO}_{2}$ following the injection of both substrates have been used to estimate the amount of TGFA retransported in the blood as UFA prior to oxidation. The oxidation of palmitic acid proceeded at a similar rate and yielded comparable specific activities in $\mathrm{CO}_{2}$ regardless of the form injected. However, a large fraction of the oxidized TGFA did not appear in the plasma as UFA, indicating that retransport as UFA is not obligatory in the utilization of exogenous triglyceride. Carbohydrate feeding de- 
creased both the oxidation and amount of TGFA returned to the blood as UFA.

\section{REFERENCES}

1. Havel, R. J., and Fredrickson, D. S. The metabolism of chylomicra. I. The removal of palmitic acid-1-C $\mathrm{C}^{14}$ labeled chylomicra from dog plasma. J. clin. Invest. 1956, 35, 1025.

2. Havel, R. J., Eder, H. A., and Bragdon, J. H. The distribution and chemical composition of ultracentrifugally separated lipoproteins in human serum. J. clin. Invest. 1955, 34, 1345.

3. Bragdon, J. H. Colorimetric determination of blood lipides. J. biol. Chem. 1951, 190, 513.

4. Sperry, W. M., and Webb, M. A revision of the Schoenheimer-Sperry method for cholesterol determination. J. biol. Chem. 1950, 187, 97.

5. Stewart, C. P., and Hendry, E. B. The phospholipins of blood. Biochem. J. 1935, 29, 1683.

6. Gordon, R. S., Jr. Unesterified fatty acid in human blood plasma. II. The transport function of unesterified fatty acid. J. clin. Invest. 1957, 36, 810.

7. Borgström, B. Investigation on lipid separation methods. Separation of cholesterol esters, glycerides and free fatty acids. Acta physiol. scand. 1952, $25,111$.

8. Laurell, S. Turnover rate of unesterified fatty acids in human plasma. Acta physiol. scand. 1957, 41, 158.

9. Savary, P., and Desnuelle, P. Analyse chromatographique des melanges contenant des acides gras, des monoglycerides, des diglycerides et des triglycerides. Bull. Soc. chim. Fr, 1954, 936.

10. Hirsch, J., and Ahrens, E. H., Jr. The separation of lipide classes by silicic acid chromatography. J. biol. Chem. In press.
11. Fredrickson, D. S., and Ono, K. An improved technique for assay of $\mathrm{C}^{14} \mathrm{O}_{2}$ in expired air using the liquid scintillation counter. J. Lab. clin. Med. 1958, $51,147$.

12. Fredrickson, D. S., McCollester, D. L., Havel, R. J., and Ono, K. The early steps in transport and metabolism of exogenous triglyceride and cholesterol in Chemistry of Lipides as Related to Atherosclerosis, I. H. Page, Ed. Springfield, Ill., Charles C Thomas, 1958, p. 205.

13. Morris, B. The oxidation of $\mathrm{C}^{4}$-labelled chylomicron fat by the rat. Quart. J. exp. Physiol. 1958, 43, 65.

14. Bragdon, J. H. $\mathrm{C}^{14} \mathrm{O}_{2}$ excretion after the intravenous administration of labeled chylomicrons in the rat. Arch. Biochem. 1958, 75, 528.

15. Fredrickson, D. S., and Gordon, R. S., Jr. The metabolism of albumin bound $\mathrm{C}^{14}$-labeled unesterified fatty acids in normal human subjects. J. clin. Invest. 1958, 37, Nov. In press.

16. Weinman, E. O., Chaikoff, I. L., Dauben, W. G., Gee, M., and Entenman, C. Relative rates of conversion of the various carbon atoms of palmitic acid to carbon dioxide by the intact rat. J. biol. Chem. 1950, 184, 735.

17. Stephenson, J. L., and Fredrickson, D. S. A mathematical analysis of the metabolism of labeled fatty acids. To be published.

18. Morris, B., and French, J. E. The uptake and metabolism of $\mathrm{C}^{14}$-labelled chylomicron fat by the isolated perfused liver of the rat. Quart. J. exp. Physiol. 1958, 43, 180.

19. Bragdon, J. H., and Gordon, R. S., Jr. Tissue distribution of $\mathrm{C}^{14}$ after the intravenous injection of labeled chylomicrons and unesterified fatty acids in the rat. J. clin. Invest. 1958, 37, 574.

\section{SPECIAL NOTICE TO SUBSCRIBERS}

Post Offices will no longer forward the Journal when you move.

Please notify The Journal of Clinical Investigation, Business

Office, 333 .Cedar Street, New Haven 11, Conn., at once when you have a change of address, and do not omit the zone number if there is one. 